\title{
SITUATIONAL ANALYSIS OF ROLE OF BILINGUALISM ON EARLY CHILDHOOD EDUCATION WITH SPECIAL REFERENCE TO QUETTA CITY.
}

\author{
Nousheen Naseer \\ MPhil scholar sociology \\ Balochistan study center.
}

\section{Dr, Naima Saeed}

Assistant Professor

University of Karachi.

\author{
Abdul Nasir Kiazai, \\ Assistant Professor, \\ Institute of Education and Research, \\ University of Balochistan
}

\begin{abstract}
.
Multiple factors rests in nation's growth but educational system plays a vital role in the development of a nation.The aim of this research article is to explore the role of bilingualism in early childhood education and also to investigate that multilingual educational system can be applied and run in a society, which is linguistically diverse like Pakistan and also investigates teacher's experiences in primary schools, addressing children from different cultures and languages. To address the issue we randomly investigated 300 respondents from different primary schools of Quetta City. A mixed approach (qualitative and quantitative) was used in this investigation. The primary data was collected through teacher's questionnaire survey and observation. On the other hand, secondary data included books, journal articles and websites. Data were analyzed using the Statistical Package for Social Science (SPSS).The findings of this study revealed that the proficiency in Urdu, and also analyzing an approach from which age the children are at their best to understand, start or adopt second language and even speak more fluently.
\end{abstract}


Pertinently that is the age it can also be judged the children are mixing up the primary and secondary languages. The findings of the study reveals that $52.7 \%$ respondents were excellent in Urdu language, $46.7 \%$ respondent suggested the best age of 4-6 year to start the second language, 59\% respondents were of the view that children can mix-up primary and secondary languages. $61.3 \%$ agreed upon the bilingualismin theearly ages. The survey concludes the bilingualism can effect on the education of the children at early age. Keeping in view the multilingualatmosphere of the Quetta city it is recommended that monoligualism is the best option of the children to be adopted in education system for better understanding.

Key words; Bilingualism, Early childhood, Education, Quetta city

\section{INTRODUCTION}

Every corner of the world children are learning languages which are different from their native language when the children join schools they must learn the majority group.InPakistan's education system English and Urdu both are being promoted in private or elite schools whole education is provided in English and in Government schools the medium of instruction is Urdu.Urdu is the national language of Pakistan is a multilingual country and people speak different languages for whom neither Urdu nor English is their mother tongue. They receive education in second and third languages due to which they face problems in understanding and conceptual ideas so it effects their cognitive development. Language plays an important role in Education and it is also considered a mark of identity.We use language to communicate with people express our ideas thoughts and our feelings to others through our culture and language people identify us.All over the world majority of people 
are multilingual or bilingual .In a study of European commission (2006) 56\% people told that they can speak another language than their mother tongue and it is also noticed that in many countries of the world the percentage is high .United states is generally a monolingual society but one fifth of the population told that they can communicate in other languages too than English.

The research shows that more than 66 percent of the world's children are bilingual. When the bilingual children communicate in one language the other language is also active on that time if a person listens a new word the sound of that sound of the word comes in a consecutive directions. After a long time when the word ended the system of the brain starts to active a lot of words which match with the sign.

Language is a system of communication based upon words, sounds, grammar, concepts, voice, gestures and written symbols. Animals also have their own communication system but their communication is limited and human communication is unlimited. Some researchers have estimated that in all over the world majority of the population use more than one language. Language play a key role in child's Education and the source of communication must be as easier that a child can understand the material which he or she is going to learn at school or any other learning place mostly primary language is spoken at home but most of the cases multi languages are spoken at home further in globe we can find such a cases easily where children are learning different languages at home primary language means the language which is learnt by the child from family or primary group and that language is called the language of thoughts and the only language which is unforgettable to till death means this is the first step of socialization which an individual learns from parents that is called the native of primary language 
which play its role in whole the life and that can be called the language of understanding.

Secondary language means not native language or the language of your thoughts mostly the secondary languages are used in academic institutions or the secondary language means the all other languages which an individual seeks other than his or her mother tonguebut this is the human brain which can read,write, speak and can understand many languages. These people are called multilingualthe language plays vital role in learning because the source of communication makes it easier for an individual to learn or practice accordingly majority of nations are focusing to educate their children especially in early ages in their primary language because primary learning in early ages can help the children to boost up their performance in their early education because the primary language is gained by the children through environment while learning the primary or native language children do not need to effort a lot the differences between the primary and academic language can effect on the child's performance badly in such a cases children get confused regarding the concepts which they have developed in their native language. Today all around the world including United Nations are focusing on the first or primary language for teaching and learning. According to UNESCO and other international agencies related to early child education, children's right and linguistic differences argue strongly for the pedagogical imperative of using a children own language as the source of instruction and international agreement regarding the importance of the use of primary language in education is reflected in many declaration and recommendationsAccording to many researchers that many children who learn the second language and ignores their own native language they lose their mother tongue. 
Mother tongue has a very strong influence in child's development. First language and sounds which we hear plays a very important role to determining our thoughts and sentiments. The personality of a child also depends on what conveyed to him by his mother tongue, that why the psychologists says that when we communicate with children we must choose best words ,nice expressions and strong vocabulary because it matters a lot. A child's main conception of the world around him,learning different concepts,awareness about survival all will start with his first language.

Children deliver their first words, first feelings, their joys and worries in their own mother tongue and they have an emotional attachment with their mother tongue. Childhood period is very important period of our life so mother tongue plays a vital role in child's personality development,mother tongue shapes our way of thinking,our emotions and mystical world.A strong relationship between mother and their children is established by feelings of love,kindness,emotions and also with oral communication. When child communicate with their parent in their own language, a direct connection forms between their mind,heart and their speech. Our personality, behavior our characteristics, humility,faults, bashfulness, our talent abilities all exposed through our mother tongue. According to "Nelson Mandela" if you talk to a man in a language which he understands that goes to his head if you talk to him in his language that goes to his heart. People are emotionally attached with their mother tongue.

A child is emotionally attached with his family parents, relatives,customs, past history,beliefs religion and his mother tongue .Mother tongue connects the child with his society and culture. Culture form the identity of children. Many children who migrated from one country to another and they cannot communicate in their mother tongue they will face 
identity crisis. Children who loses their identity they will try to seek an alternate identity.Parent who loves their mother tongue and culture they never neglect their own language they maintain it in all circumstances. If we are living in a multicultural society we must learn and respect the other cultures.

It is easier for the majority of children to learn the native languages without any efforts however there are different variations in the rate at which the children learn languages with exactly seven percent of children demonstrate impairments in these all skills there is strong relationship between child's primary language and his performance in school and awareness regarding this is reflected in majority of policy and practices that gives importance to the child's language as a source of raising attainment.

While understanding the effects on child's language development in the population that can be helpful evidence based on policies development in the factors that predict variations may point out significance areas for interventions. those effects can be generally conceptualized as primary to the Childs's environment such an effects are identified to be dynamic and interacting, there are well established models of risk associated with social disadvantages and week cognitive and language development in the early years of children although such a models are not well comprehended and depend of one measures or proxies like mother's level of education. This study gives the opportunity to understand how the children primary language interact with their early environment, communication and development in languages and development in prediction their ability at early education. Researches show that children from lower socio demographic backgrounds have poor language skills when they start their schooling.Pakistan is a country of multilingual regional languages and all the languages have their own historical cultural and social importance. Urdu is the national language 
and English is the official language of Pakistan and its widely used in private schools colleges and universities of Pakistan.

Language is a cultural influence that shapes individual's personality, more so for a multilingual person, whose personality is shaped by multiple languages. Psychiatrist Frantz Fanon states;

"To speak means to be in a position to use certain syntax, to grasp the morphology of this or that language, but above all to assume a culture, to support the weight of a civilization."

Personality is not one-dimensional; it is a combination of qualities that form an individual's distinct character. Multilinguals have a much more complex personality than monolinguals because of the distinctive cultures. This means to have knowledge about more people and cultures but also having to juggle among all the different personalities.

According to F Genesee Genesee, F (1995). The bilingual children never become dominant in any language but the bilingual children have the same ability to seek both languages at same time. bilingual and multilingual children have language development in different forms, and vocabulary is one of them. He described that all the children have partial memory abilities but the bilingual children collect words from both languages instead of one language.

He described that usually bilingual children learn language skills very fast, its important for parents speak the majority language and as well as their native language at home because language is a part of our culture and identity.Sometimes bilingual children become confused when they are using both languages at a time they mix up the languages. Some parents think that the children are getting confused but the researchers are not agreed about that.The children mix languages because they don't have enough vocabulary 
in both languages that's why they use words from other languages. But the children understand both languages and sometimes they mix up languages because the children are in learning process. Mixing languages is not a problem because in early age the children can mix the languages but as they grow up they will stop mixing languages

Noam Chomsky is an American philosopher, social critic ,linguistic Political activist and cognitive scientist he challenged all previous ideas about achievement of language in his first book which published in 1957 name of the book was "Syntactic Structures,"(Chomsky, Noam. 2002) Chomsky rejects the idea that whole languages should be learned once more by every child .He says that everywhere in the world all the normal children are born with a tough strengthened composition which facilitate them to grip the main working of language, He believes that all the children born with the ability to learn any language .He said that the child adopt the language of the atmosphere from the accessible possibilities in the brain. Chomsky said that the brain controls the understanding and creation of speech .According to Chomsky learning a language children did not needs any formal type of teaching. He said that ideal age for learning a language is from 3 years to 10 years. Parents never perused the child to speak a language the child observes and learn the language by his own abilities.If the school administration reject the children ,s mother tongue is to reject children and their identity . When children joins school the administrators bound them to adopt the school language and leave your mother tongue and the children also leave a main part of their identity. Due to rejection they don't wants to participate in class activities and they lose their confidence level too.

Teachers never accept the language and cultural diversity of students at school .It's important for teachers they must be practical and protect the 
identity of their students by having different posters of different languages and motivate the children to write in their own language in adding the school language and the teacher must create an environment where all the students participate linguistic and cultural skills.

\section{Study Area.}

The researcher selected Quetta District of Balochistan.Balochistan is the one of the four provinces of Pakistan and also the largest province regarding area with the total population of 12344408 according to the census 2017 and a large number of Afghan refugees are also part of the population. The population size is very huge and a large number of schools are established in the city to fulfill the educational needs of the population .Quetta is a multilingual and multicultural city Balochi,Brahvi and Pashto are provincial languages of Balochistan and the other languages spoken here including Panjabi Hazargi Sindhi and Siraiki.The province has the smallest number of educational institutions especially in the rural areas of Balochistan literacy rate is very low. This research conducted in the primary schools (boys and girls) of Quetta District.

\section{Research Methodology.}

Type of research is exploratory research and the key respondents were teachers and parents of the students of primary schools because the researcher cannot access the students of early ages due to their age factor and multilingual and multicultural ethnic groups. Samples were collected through stratified random sampling the data processed and analyzed through SPSS.

\section{Sample size and sample unit.}


Quetta is the largest city and provincial capital of Balochistan province .The total population of the city is 1,001,205 according to the census 2017.There are total 553 Government schools in Quetta city(339 boys and 214 girls schools) to fulfill the educational needs of three million students. The unit of this investigation is the teachers of primary schools. The sample size is 300 teachers (male and female) from different primary schools of Quetta city.A mixed approach (qualitative and quantitative) was used in this investigation. For data collection the major sources were questionnaires, key informants and observations.

\section{$\underline{\text { RESULTS }}$}

\begin{tabular}{|c|c|c|c|}
\hline \multicolumn{4}{|c|}{ Respondentsproficiency in Urdu } \\
\hline Sr. No & Respondents proficiency in Urdu & Frequency & Percentage \\
\hline 1 & Excellent & 158 & $52.7 \%$ \\
\hline 2 & Fluent & 113 & $37.7 \%$ \\
\hline 3 & Average & 28 & $9.3 \%$ \\
\hline 4 & Not Fluent & 1 & $.3 \%$ \\
\hline & Total & 300 & $100.0 \%$ \\
\hline
\end{tabular}

Findings of the study showed that $52.7 \%$ of the respondents proficiency in Urdu is excellent $37.7 \%$ of respondents were fluent in Urdu $9.3 \%$ were in average and only $3 \%$ were not fluent in Urdu.

\section{What is the best age to start second languages?}

\begin{tabular}{c|l|c|c} 
Sr. No & $\begin{array}{l}\text { What is the best age to } \\
\text { start second languages? }\end{array}$ & Frequency & Percentage \\
\hline $\mathbf{1}$ & 2.5 to 4 years & 69 & $23.0 \%$
\end{tabular}




\begin{tabular}{|c|c|c|c|}
\hline 2 & 4 years to 6 years & 140 & $46.7 \%$ \\
\hline 3 & $6 \&$ above & 91 & $30.3 \%$ \\
\hline & Total & 300 & $100.0 \%$ \\
\hline
\end{tabular}

The above table showed that $46.7 \%$ respondents view was that ideal age for starting second language is 4 to 6 years while $30 \%$ respondents view was that the best age is 6 and above.

Do the children mix up the languages?

\begin{tabular}{l|l|l|l} 
Sr.No & $\begin{array}{l}\text { Do the children } \\
\text { mix the languages }\end{array}$ & Frequency & Percentage \\
\hline $\mathbf{1}$ & Yes & 177 & $59.0 \%$ \\
\hline $\mathbf{2}$ & To Some extend & 99 & $33.0 \%$ \\
\hline $\mathbf{3}$ & No & 24 & $8.0 \%$ \\
\hline \multicolumn{2}{r}{ Total } & $\mathbf{3 0 0}$ & $\mathbf{1 0 0 . 0 \%}$
\end{tabular}

In the above table more than half respondents mix the languages while $33 \%$ respondents showed that children mix languages in some extantthe first language with $2^{\text {nd }}$ when they communicate in $2^{\text {nd }}$ language.

\section{Children can understand and speaks second language frequently?}

\begin{tabular}{l|l|l|l} 
SrNo & $\begin{array}{l}\text { Children can } \\
\text { understand and speaks } \\
\text { second language } \\
\text { frequently? }\end{array}$ & Frequency & Percentage \\
\hline $\mathbf{1}$ & Yes & 85 & \\
\hline $\mathbf{2}$ & To some extend & 148 & $28.3 \%$ \\
\hline
\end{tabular}




\begin{tabular}{r|l|l|l}
$\mathbf{3}$ & No & 67 & $22.3 \%$ \\
\hline & Total & $\mathbf{3 0 0}$ & $\mathbf{1 0 0 . 0 \%}$
\end{tabular}

In the above table $49.3 \%$ respondents showed that children can understand and speaks the $2^{\text {nd }}$ language in some extent while $22.3 \%$ answered that children don't understand and speaks the language of instructions.

What is your opinion which one is the best for the students of early ages?

\begin{tabular}{c|l|c|c} 
SrNo & $\begin{array}{l}\text { What is your opinion which } \\
\text { one is the best for the students } \\
\text { of early ages? }\end{array}$ & Frequency & Percentage \\
\hline $\mathbf{1}$ & Mono-lingualism & 55 & $18.3 \%$ \\
\hline $\mathbf{2}$ & Bilingualism & 184 & $61.3 \%$ \\
\hline $\mathbf{3}$ & Multilingualism & 61 & $20.3 \%$ \\
\hline \multicolumn{2}{r|}{ Total } & $\mathbf{3 0 0}$ & $\mathbf{1 0 0 . 0 \%}$
\end{tabular}

When we asked the opinion of respondents that which one is the best for the students of early ages according to the results $61.3 \%$ of respondents showed that bilingualism is best while $20 \%$ preferred multilingualism and $18.3 \%$ respondents were in the favor of mono lingualism.

\section{Discussion}

Provision of education is the core responsibility of the parents to their children. The Government play affective and efficient role in providing education to each and every child of his country contrary to discretion of gender, civilization, culture and norms. Education is the basic right of children of the state and state stands responsible to provide the same in equal 
standards to meet the national and international challenges. The research area selected for study is Quetta city, which is significantly predominant of different local languages. MostlyBalochi,Brahvi and Pashto are cultural languages of Balochistan and the other languages including Panjabi, Hazargi, Sindhi and Siraiki spoken. The basic draw back of the research is that Urdu and English are not the mother languages, and unfortunately those are main and mandatory languages of our academics and curriculum. Psychologically which can directly and indirectly affect the education of early childhood where the child first to understand the language used for educationby the teacher, then compare it with hisunderstandable multilingual surroundings and then comes the phase where he translate it in his mother tongue. Because it is the universal truth that a children can better understand each and every aspect of education in his mother tongue.

\section{Conclusion and Recommendation}

The research conducted in the different primary schools of Quetta city to analyze the role of bilingualism influencing the early childhood education in Quetta city wherechildren are living in multilingualenvironment and medium of educational curriculum is based on the language other than their mother tongue which is not commonly spoken around. The initial grooming of the child in educationis at the age of 4-6 year. It is recommended that bilingualism impede cognitive development. And the study discusses that to examine the cognitive development in bilingual children with regard to metalinguistic awareness, concept formation, and analogical reasoning. A case is made for additive bilingual instruction in early childhood programs as a means of reinforcing the productive and receptive knowledge of the first language during this critical period of linguistic, social, and cognitive development. 


\section{REFERENCES.}

Ball, J. (2010). Enhancing learning of children from diverse language backgrounds: Mother tongue-based bilingual or multilingual education in early childhood and early primary school years. Victoria, Canada: Early Childhood Development Intercultural Partnerships, University of Victoria.

Cummins, J. (2001). Bilingual children's mother tongue: Why is it important for education. Sprogforum, 19, 15-20.

Chomsky, N. (2002). Syntactic structures. Walter de Gruyter.

Lee, P. (1996). Cognitive development in bilingual children:

A case for bilingual instruction in early childhood education. Bilingual Research Journal, 20(3-4), 499-522.

Manan, S. A., David, M. K., \&Dumanig, F. P. (2015). Disjunction between language policy and children's sociocultural ecology-an analysis of Englishmedium education policy in Pakistan. Language and Education, 29(5), 453473.

Patrinos, H. A., \&Ariasingam, D. L. (1997). Decentralization of education: Demand-side financing (Vol. 292). World Bank Publications.

Rahman, T. (2010). National Institute Of Pakistan Studies October 2010.

Martin-Jones, M., \&Saxena, M. (2003). Bilingual resources and'funds of knowledge'for teaching and learning in multi-ethnic classrooms in 
Britain. International Journal of Bilingual Education and Bilingualism, 6(34), 267-282.

Cummins, J. (2007). Rethinking monolingual instructional strategies in multilingual classrooms. Canadian Journal of Applied Linguistics/Revue canadienne de linguistiqueappliquée, 10(2), 221-240.

Baker, C., \& Jones, S. P. (Eds.). (1998). Encyclopedia of bilingualism and bilingual education. Multilingual Matters.

Miles, C. (1996). Bilingual Children in Special Education: Acquisition of Language and Culture by British Pakistani Children Attending a School for Pupils with" Severe Learning Difficulties.". 